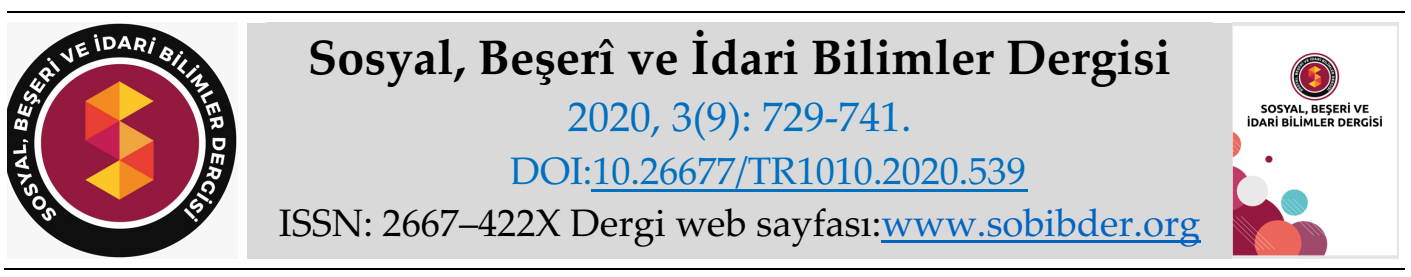

$\underline{\text { KAVRAMSAL MAKALE }}$

\title{
Video Oyunlardaki Transhümanist Karekterler: NieR: Automata, Detroit: Become Human ve DeusEx: Mankind Divided
}

Sercan D. ARISOY, İngiliz Dili ve Edebiyatı Yüksek Lisans Öğrencisi, İstanbul Aydın Üniversitesi, Sosyal Bilimler Enstitüsü, İstanbul, e-posta: sercan.arisoy@gmail.com

ORCID: https://orcid.org/0000-0003-0606-9554

Öz

Video oyunlar bir sektör olarak çapını genişletmeye ve yeni hedeflere ulaşmaya devam ediyor. Bazıları için, sektörün finansal kazanım ile çok yakından bağlantılı olmasından ötürü, video oyunların sanat eseri sayılamazken diğerleri, ilk gruba nazaran video oyunlara karşı daha sempatik yaklaşır ve video oyunların sanatsal potansiyelini irdeler. Durmaksızın gelişen teknolojisiyle, video oyunlar yapımcılarına değişik hikâyeler yaratıp video oyuncularla etkileşime geçebilecekleri çeşitli yöntemler sunar. Bu oluşumun sağladığı sanatsal özgürlük, geleceğin nasıl olabileceğini merak edip, fantezi kuran sanatçılar için ilginç bir araç olabilir. Video oyunlar da kitapların ve filmlerin çokça incelediği transhümanizm ve posthümanizm konuları üzerinde durmuşlardır. Video oyunların, çoktan var olan sanat eserleri ile arasındaki bu benzerlik, video oyunlarını sanat eseri olarak sayılmasının vaktinin gelip gelmediği sorusunu akla getirir. Bu çalışma, son zamanlarda sıkça adı geçen video oyunların sanat potansiyelini, video oyunlardaki transhümanist karakterleri incelemek ve var olan sanat dalları arasındaki benzerlikleri göstererek cevaplandıracaktır.

Anahtar Kelimeler: Transhümanizm, Posthümanizm, Video Oyunlar, Android, Sibernetik Geliştirme.

Makale Gönderme Tarihi: 09.06.2020

Makale Kabul Tarihi: 02.09.2020

\section{Önerilen Atıf:}

Arısoy, S. D. (2020). Video Oyunlardaki Transhümanist Karekterler: NieR: Automata, Detroit: Become Human ve DeusEx: Mankind Divided, Sosyal, Beşeri ve İdari Bilimler Dergisi, 3(9): 729-741. (c) 2020 Sosyal, Beşerî ve İdari Bilimler Dergisi. 


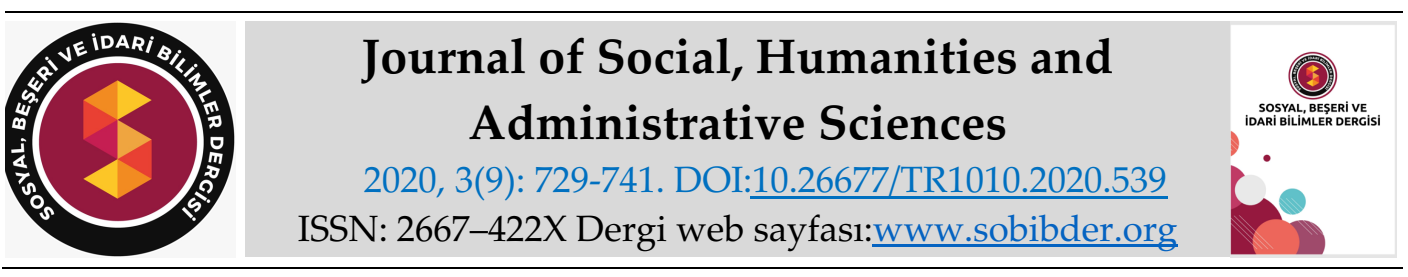

\title{
CONCEPTUAL PAPER
}

\section{Transhumanist Characters in Video Games: NieR: Automata}

Sercan D. ARISOY, MSc. Student, İstanbul Aydın University, Social Sciences Institute, İstanbul, e-mail: sercan.arisoy@gmail.com

\section{ORCID: https://orcid.org/0000-0003-0606-9554}

\begin{abstract}
Video games as an industry continues to grow in scale and reach new milestones. Accelerated popularity of the medium has surfaced debates among the academia about the nature of video games. For some, video games cannot be considered works of art due the industry's relation to financial profit. While others are more sympathetic than the former and see the potential ways video games can produce art. With its ever-growing technology, video games provide interesting ways for game designers to make stories and interact with players on various ways. Artistic freedom the medium provides can be an interesting tool for those who wish to fantasize and envision what the future may look like. Video games have explored similar topics of transhumanism and posthumanism that film industry and novels have discussed. The similarity video games have with existing styles of art raise the question if it is about time video games should be considered art. This study focuses on the hot topic of video games as an art form through transhumanist characters seen in video games.
\end{abstract}

Keywords: Transhumanism, Posthumanism, Video Games, Android, Cybernetic Enhancement Received: 09.06.2020

Accepted: 02.09.2020

\section{Suggested Citation:}

Arısoy, S. D. (2020). Transhumanist Characters in Video Games: NieR: Automata, Journal of Social, Humanities and Administrative Sciences, 3(9): 729-741.

(c) 2020 Sosyal, Beşerî ve İdari Bilimler Dergisi. 


\section{Gíriş}

Video oyun kültürü gün geçtikçe yaygınlaşmaya başlamıştır. Teknolojinin gelişmesiyle, video oyunlar da gelişir. Mobil cihazlarda yer alan oyunlar da düşünüldüğünde, interaktif eğlence sektörü, gündelik hayatımızın vazgeçilmez bir parçası haline gelmiştir. Grand Theft Auto $V$ (Rockstar, 2013) piyasaya sürüldüğünde, oyun satış rekorları kırıp, en hızlı satan eğlence ürünü olmuştur (Vikipedi, 2020). Popülerleştikçe, video oyunlarla çokta ilgili olmayan insanlar, video oyunları anlamaya çalışmaya başladılar. Bu girişim, video oyunların toplumdaki imajını yavaşça değiştirmeye başladı.

Video Game Theory Reader (Bernard, 2003:8) kitabının yazarlarının da belirttiği üzere, video oyunlar 1993 yılından beri Fransa'da onuncu sanat dalı olarak kabul görür. Bu bildirgeden yirmi altı yıl sonra, 2019 yılında, yangından zarar gören Notre Dame Katedrali'ni onarmak için, Fox Business (2019) yetkililerin Assassin's Creed Unity (Ubisoft, 2015) adlı oyunu referans olarak kullanmayı planladıklarını açıkladı. Bahsi geçen oyunun hikâyesi Fransa'da geçtiğinden, Assassin's Creed Unity adlı oyun, Notre Dame Katedrali'nin neredeyse kopyası sayılabilecek kadar ayrıntılı ve üç boyutlu bir modelini içinde barındırır. Tarihin bu kadar önemli bir parçasının onarımında oynadığı rol, video oyunları daha saygıdeğer bir konuma getirir.

Günümüzde, video oyunlar çocukların vakit öldürmek için uğraştığı uygulamalar değil; tarih, sanat, felsefe, tasarım ve programlamanın içinde bulunduğu interaktif tecrübeler sunan bir kazana benzer. Hızlı ve sürekli gelişmekte olduklarından, video oyunları tam olarak ne olduklarını tek bir sıfat altında tanımlamak güçtür. Ancak, topluma olan bağları her geçen gün kuvvetlenmiş, adından daha fazla söz ettirmeye başlamıştır. Bu nedenle, tanımlanma gereksinimi kaçınılmazdır.

Video oyunlar, oyun geliştiricilerine sunulmuş olan sanatsal özgürlük ve interaktif tecrübe teknikleriyle video oyuncuların hikâyede aktif rol aldıkları hikâye anlatım araçları haline gelmiştir. Video oyunlar, teknoloji ve bütçe olarak büyümeye devam eder. Gelişimini tamamlamış oyunların büyük bütçeli olanları, filmler kadar muhteşem ve inanılır gözükebilir. Video oyunlar daha büyük kitlelere ulaşabilmek için çeşitlilik gösterir. Cep telefonları hızlı bir şekilde akıllı telefonlara evrimleşirken, video oyunlar için yeni bir platform türer. Bu platform neredeyse herkese ulaşabilen bir market. Akıllı telefonlar için geliştirilen oyunlar genellikle oynaması ücretsiz olup, kullanıcıya para harcatma odaklı geliştirilmiş olsa da video oyunları herkese ulaştırabilecek ölçüde yaygınlaştırarak, gündelik yaşam ile video oyunların birleşmesinin en gözle görülür örneği olmuştur.

Posthüman temalar, video oyunların hikâyelerinde sıkça kullandıkları bir konudur. Video oyunların posthüman temaları nasıl kullandıklarıyla ilgili çalışmalar mevcuttur. Tanya Krzywinska ve Doughlas Brown (2015: 201.) video oyunların (ya da video oyun yapan stüdyoların) oyuncuları müşteri gibi görmesine dikkat çeker "Oyunların tasarım süreci tamda, Vitruvius Adamı gibi, oyuncuları müşteri boyutuna sı̆̆acak şekilde yapılmıştır; posthüman son derece hümanist hedeflerle dizginlenmiştir." Alıntılanan metnin yazarları, oyunculara, görevlerini tamamlamaları için, oyunun işaretler gösterip, ipucu ya da göstergelerle tecrübeyi kolaylaştırarak, oyunculara ilerlemelerinde yardımcı olduğunu savunur. Vurgulandığı üzere, gerçek hayatı taklit eden tahmin edilemez durumlar yerine, video oyunlar, sanal ortamlarını ezberlenebilir algoritmalar üzerine kurar. Yazarların söylemi, işlevsellikleri ezberlenebilir olduğundan, video oyunların amacının, oyuncuları gerçek problemlerle karşılaştırmaktansa, onlara zevk vermeye odaklandığını savunur. Brown ve Krzywinska (2015) tarafından yazılanlara göre, tüketimi özendirme sisteminden etkilendiği için, video oyunların posthüman temaları, posthümanizmi bir bütün olarak ilerletmektense, onu etrafında bir hikâye oluşturmak için bir temel olarak kullandığını öne sürer. 
Brown ve Krzywinska (2015) aynı zamanda bu tanıma uymayan video oyunlardan da örnek verir. Ancak, belirttiklerine göre bu tür oyunlar genellikle popüler değildir. Video oyunlarla ilgili daha da örnek vermeden önce, yazarların söylemleri üzerine daha ayrıntılı durmak, ilginç ayrıntılar ortaya çıarabilir. Türk Dil Kurumu, 'müşteri' kelimesini, hizmet veya mal alan ve karşıllğında ücret ödeyen kimse olarak tanımlar (www.sözlük.gov.tr,). Brown ve Krzywinska tarafından makalenin yazım dili olan İngilizcedeki 'customer' kelimesi, Türkçedeki 'müşteri' kelimesiyle benzer bir anlam taşır (https://www.oxfordlearnersdictionaries). Ancak posthümanizm çerçevesi altında, 'consumer' kelimesi, kendi gerçeğini şekillendiren bir kimsedense, en yüksek potansiyelinden alıkonulan ve kontrol altında tutulan bir insana anlamında kullanılıyor olabilir. Bu anlam düşünüldügünde, oyuncular oyunun programlanan kısmını oynar ve geliştiricilerin popüler gördüğü kısıtlı yollar aracılığıyla tatmin duygusunu hissederler. Diğer bir yönden, üretici kontrollü içerik diğer eğlence ürünleri için de geçerlidir. Okuyucular, yazarların yazdıkları kadarını okurlar. Seyirciler, yönetmenin görüşü doğrultusunda kameralar ile çekilen kadarını izler. Tiyatro izleyicileri, oyun yazarları tarafından yazılanları dile getiren oyuncuları izler ve duyarlar. Yazarların söyleminin aksine, konu kendi tecrübesini yaşamak olunca, oyuncunun aktif iletişim ve oyuncu tarafından yapılan seçimlere göre şekillenen hikâyeleriyle, video oyunlar en kişiselleştirilmiş hikâye anlatım yöntemidir. Oyun dünyası içinde oyuncuların belli görevlere yönlendirilmesi, hikâye elementlerini kişiselleştiremeyecekleri ve sunulan hikâye konusunda kendi fikirlerini oluşturamayacakları anlamina gelmez.

Brown ve Krzywinska (2015:200) ezberlenebilir ve yardımcı mekanikleri yüzünden eleştirdikleri oyunun adı Orcs Must Die'dır (Robot Entertainment, 2011). Video oyun endüstrisinin sürekli değişen ve gelişen yapısı, tek bir oyun üzerinden yapılan eleştirilerin çabucak geçersiz olmasına sebep olur. Orcs Must Die adlı oyunun çıkışından beri, zorluk seviyeleri ve oyuncuya yardım etmeyen yapısı ile bilinen birçok oyun piyasaya çıkmıştır. Bunlardan biri Cuphead (Stüdyo MDHR, 2017) olabilir. 1930'ların çizgi film stilindeki oyun, "Run and Gun" ve "Boss Rush" şeklinde, ikisi de birbirinden zorlayıcı oyun modları içerir. Oyunda, oyuncu sürekli düşman karakterlerden gelen mermileri atlatmaya çalışır. Güçlü düşmanların birden çok safhası vardır ve mücadele devam ettikçe, saldırı ve hareket şekillerini değiştirirler. Bu mekanikler oyunu ezberlenebilir olmaktan uzaklaştırır. Oyun, oyuncunun yeteri kadar gözlem yeteneği ve hatırı sayılır tepki seviyesinin olmasını gerektirir.

Çeşitli oyunları örneklendirirken, hikâyesinde posthümanizm temaları taşıyan ve aynı zamanda oyuncunun ilerlemesine yardım eden örnekler vermek iyi olabilir. Aslı televizyon dizisi olan Back to the Future (Telltale Games, 2010), bölümler halinde yayınlanan bir bulmacalı macera oyunudur. Hikâyede bulunan posthüman öğe zamanda seyahat edebilen modifiyeli Delorean arabasıdır. Oyun aynı zamanda oyuncunun bulmacaları çözmesi için çeşitli seviyelerde ipuçları sunar. Bu ipuçları, küçük imalarla başlayıp, oyuncunun tam olarak ne yapması gerektiğini ayrıntılı olarak anlatan açıklamalara kadar gidebilir. Ancak yapılan yardımın seviyesi oyuncuya bağlıdır. Eğer isterse, oyuncu bütün oyun boyunca hiç yardım almayabilir. Oyunun sunduğu bu yardım seçeneği, çok daha geniş bir kitlenin oyunun hikâyesinden keyif almasına olanak tanır. Aynı zamanda birçok video oyun, daha geniş oynanış şekillerini kapsayabilmek adına, oyunu çeşitli zorluk seviyelerinde oynanabilme seçeneğini sunar. Ancak bu zorluk seviyeleri oyuncuyu kolay yoldan tatmin etme amaciyla sunulmaz. Çoğu zaman oyuncular, oyunu daha yüksek zorluk seviyelerinde bitirdiklerinde çeşitli gizli içeriklerle ödüllendirilir. Resident Evil 4 (Capcom, 2005), God of War (SIE Santa Monica Stüdyoları, 2010) gibi oyunlar, daha zor seviyelerde oyun bitirildiğinde ana karakterin kullanabileceği alternatif kostümler sunar. Bütün bu özelliklerin hepsi video oyunların oynanış kısmı ile alakalıdır. Oyunun hikâyesi, istenilen zorlukta tecrübe edilebilir. Diğer yandan, Cuphead (Stüdyo MDHR, 2017) gibi oyunlar, hikâyenin devam etmesi 
için oyuncuların bölümleri normal zorluk seviyesinde geçmesini gerektirir. Orcs Must Die (Robot Entertainment, 2011) adlı, oyuncuya yardım etmesiyle eleştirilen oyunda bile, tuzakları güçlendirebilmek için, daha zor seviyelerde bitirildiğinde beş kafatası verilirken, daha kolay seviyelerde iki kafatası verilerek, oyuncunun gelişimini kısıtlar (TV Topes, 2020, Easy-Mode Mockery). Oyunu en kolay modda oynadığı için oyuncunun belli ölçüde kısıtlandırılması, oyuncuları kendilerine güvenlerini, sabırlarını ve reflekslerini geliştirmeye teşvik eder. Üstelik Moffit (2014), video oyunların insan beyninde hafıza güçlendirici, tepki yetenekleri ve stratejik planlama gibi bilişsel seviyedeki faydalarından söz etmiştir.

2011 yılından önce ve ötesinde, zorluklarıyla ünlü birçok oyun piyasaya sürüldü. Bunların en popülerlerinden bazıları League of Legends (Riot Games, 2009), Dota 2 (Valve, 2013), Fortnite (Epic Games, 2017), Counter Strike Global Offense (Valve, 2012) ve Overwatch (Blizzard Entertainment, 2015). Sayılan bütün oyunlar çevrimiçi oynanır ve oyuncular birbirlerine karşı mücadele ederler. Overwatch'da, çeşitli haritalarda kuşatma, koruma ve kontrol gibi oyun modlarında oyuncular altı kişilik takımlar halinde birbirleriyle karşılaşırlar. Overwatch'da karakterler zamanla güçlenmezler. Oyuncunun oyunu oynayarak geçirdiği süre, karakterlerin güç seviyesinde herhangi bir farklılık yaratmaz. Her karakterin kendine özgü aktif ve pasif yetenekleri vardır. Oyuncular farklı karakter kombinasyonları kullanarak karşı takıma üstüm gelmeye çalışır. Takım olarak oynana bir satranç oyununa benzetilebilir. Oyun çeşitli karakterlerle yapılan kombinasyonlar ve değişik yeteneklerle oluşan durumlar sunduğu için, oyuncuların karşılaştıkları senaryolar ezberlenemez. Bununla beraber, oyun geliştiricileri oyuna sıklıkla yeni karakterler ekler ve var olan özelliklerde oynamalar yaparlar. Eğer bir karakter çok güçlü olduğu için oyuncular arasında ünlenmişse, yetenekleri geliştirici ekip tarafından azaltılır.

Brown ve Krzywinska (2015: 192) oyunculara kendi hikâyelerine yön verme olasılığını sunduğundan, video oyunların film ve sinema sektörüne bir rakip olarak gelişmekte olduğunu öne sürer. Detroit: Become Human (Quantic Dreams, 2013) gibi kendi hikâyeni seç tarzındaki oyunlar, oyun boyunca yaptıkları seçimler doğrultusunda hikâyelerini şekillendirebilecekleri özgürlüğü sunan bir oynanış tarzıyla özgün bir stile sahiptir. Ancak, hikâye anlatımlarındaki kişisel seçim özgürlüğü, video oyunları film veya sinema endüstrisinin rakibi yapmaz. Tam tersine, teknoloji gelişmesiyle mümkün olan daha geniş çaplı hikâye anlatım stilleri, video oyun ve film endüstrilerinin daha fazla birlikte çalışmalarına olanak sunmuştur. Video oyunlar ve film endüstrisi arasındaki bu ortaklığı en güzel gösteren örnek Remedy Entertainment tarafından geliştirilen Quantum Break (2016) olabilir. Shawn Ashmore'un canlandırdığı ana karakteri kontrol etmenin yanında, Quantum Break'in hikâyesi oyun içi ara sahneler ve dizi formatındaki parçalardan oluşur. Bu iki stilin birleşiminden oluşan yöntem, hikâyeyi tecrübe etmek için yeni ve ilginç bir yöntem oluşturur.

Shawn Ashmore gibi, filmlerdeki performanslarıla ünlenmiş ve sonrasında oyunlarda kendilerine rol bulmuş birçok aktör vardır. Beyond Two Souls'da (Quantic Dreams, 2013), Ellen Page ve William Defoe, Jodie ve Nathan karakterlerine kendi fiziksel görünüşleri, sesleri ve hareket performanslarıyla can vermişlerdir. Hollywood tarzındaki hikâye anlatışıyla ünlenen oyun yönetmeni Hideo Kojima, Norman Reedus, Mads Mikkelsen ve Léa Seydoux ile çalışarak Death Stranding (Kojima Productions, 2019) oyunundaki karakterlere can vermekle kalmamış, oyunun hikâyesini İspanyol film yönetmeni Guillermo Del Toro ile birlikte yazmıştır. Başka bir ünlü isim olan Keanu Reeves, Cyberpunk 2077 (CD Projekt RED, 2020) oyununda Johnny Silverhand adlı karakteri canlandırır. Keanu Reeves aynı zamanda E3 2019 konferansinda, Cyberpunk 2077'ın çıkış tarihini açıklamak için sahneye çıkmıştır ve bu durum medyada yankı uyandırmıştır (Kotaku, 2019).

Seçim temelli, bölümler halinde yayınlanan oyun formatıyla ün kazanmış Telltale Games, çoktan var olan markalarla çalışıp kendi hikâyelerini yazmışlardır. Bunlardan bazıları şunlardır; Wallace 
$\mathcal{E}$ Gromit (2009), Sam \& Max (2009), Back to the Future (2010), Jurassic Park: The Game (2011), The Walking Dead (2012), The Wolf Among Us (Fables adlı çizgi roman serisinden uyarlama, 2013), Minecraft: Story Mode (2015), Batman (2016), ve Guardians of the Galaxy (2017). Konu hikâye adapte etmek olunca, Telltale Games'in de yaptığı gibi, video oyunlar sadece filmler ile sinırlı kalmaz. Kitaplar, çizgi romanlar ve hatta televizyon serilerinin bile adaptasyonu yapılabilir.

Andrej Sapkowski'nin The Witcher ve Dmitry Alexeevich Glukhovsky'nin Metro 2033 (2002) markaları, video oyun adaptasyonu yapılan kitap serilerinden iki tanesidir. Buradaki fikir, video oyunların, kendilerinden önce gelen sanat dallarına rakip olmadığı, onlardan esinlenerek, özgün yaklaşımlarını sunduklarıdır.

Teknolojiye olan ihtiyaçları, video oyunları ve transhümanizmi ortak paydada buluşturur. Aynı kökle bağlantılı olmaları, video oyunların transhümanist konulara daha 1 lımlı ve anlayışlı yaklaşmalarına bir sebep olabilir. Ancak elbette bir bireyin transhümanizmi anlaması için, bilgisayar teknolojilerine sempati duyması gerekli değildir. Öte yandan bu sempati yararlı olabilir. Teknolojiye sempati duyan bir kimsenin, transhümanizme karşı daha az önyargısı ve yanlış kanısı olabilir.

Video oyun endüstrisi gibi geniş ve çeşitlilik gösteren bir mecrayı keskin hatları olan bir açıklama getirmek güçtür. Gelişen teknoloji yeni hikâye anlatma yöntemleri sunarken, video oyunlar, grafiksel bakımdan filmler ile boy ölçüşecek seviyeye ulaşmıştır. Böylece video oyunlar akademik araştırmacıların da ilgisini çekmiş ve iki taraf da birbirini anlamaya çalışmaya başlamıştır. Bu çalışma, tema, oyun mekanikleri ve karakterler açısından video oyunların nasıl transhümanizmi ele aldıkları üzerinde duracaktır.

\section{DETROIT: BECOME HUMAN ve İNSANSI ROBOT FİKRİ}

Video oyunlar sanat eseri tanımını yeniden yapılandırırken, oyuncular kontrol ettikleri karakterle kurdukları özel bağın keyfini çıkarırlar. İnsanların teknoloji ile olan etkileşimleri oyundaki karakterler için de bir referans noktası olmuştur. Gelecekte teknolojiyle iç içe yaşayan bir toplumun nasıl etkileneceğini betimlerken, teknolojiyle iç içe geçmiş karakterler oyuncuların kontrolüne verilir. Oyuncular bu karakterleri kontrol ederken, hikâyeyi teknoloji ile iç içe geçmiş karakterlerin perspektifinden tecrübe ederler.

Detroit: Become Human (2018) yönetmeni ve yazarı olan David Cage'in imza stilini taşır. Oyunun hikâyesi, oyuncunun verdiği kararlara göre şekillenir. Filmler, etkileyici hikâyeleri muhteşem görsellerle birlikte sunmasıyla bilinir. Kendi maceranı seç türündeki oyunlar, filmlerin sunduğunun bir adım ötesine geçerek, uzun hikâyeleri, güçlü görseller ve oyuncuların seçimleriyle anlatır. Oyuncuya olan odak, oyuncuların seçimlerinin oyunda yarattığı etkiden gelir. Klasik oynanış mantığına göre, eğer oyuncunun kontrol ettiği karakter ölürse bir oyun bitiş ekranıyla karşılaşılır ve oyuncu en son kayıt noktasından tekrar başlar. Ancak seçim temelli oyunlar genellikle kontrol edilen karakter ölse bile devam eder. Oyuna devam edebilmek adına, oyuncuya hikâyede kontrol edebilmesi için birden fazla karakter verilir. Eğer bu karakterlerden biri oyuncunun aldığ 1 kararlardan ötürü ölürse, hikâye o karakterler olmadan devam eder. Elbette bu karakterler hikâyeye devam etmedikleri zaman, süregelen olaylar farklıllk gösterir. Detroit: Become Human'nın durumunda, oyuncu üç karakter kontrol eder ve bu karakterlerin hepsi androiddir. Hikâye gelecekteki Detroit şehrinde, androidlerin sosyal yaşama adaptasyonlarını konu alır. Karel Čapek'in tiyatro oyunu R.U.R'da da (1920) bahsettiği toplumsal tedirginliğe sıkça değinirken, insan olmanın ne demek olduğunu sorgular.

İnsanlara son derece benzemeleri yüzünden, hümanoid robotların kavramı bile insanlar için bir endişe kaynağıdır. Görünüş olarak insanı andırmayan robotlar (Boston Dynamics'in 
geliştirdikleri gibi) insanlarda aynı tedirginliği yaratmayabilir. Tedirginliğin kaynağı robotların insanlar ile karıştırılma olasılığı olabilir. Ancak her robot, insanın yerini alma amacıyla geliştirilmez. Hayvanları andıran robotlar da vardır. SoFi (Tech INsider, 2018) balık şeklinde tasarlanmış ve denizin derinliklerini araştırma merakından doğmuş bir robottur. Robotun amacı, insanların ya da makinaların giremeyeceği kadar dar olan alanları inceleyip görüntülemektir. Spy in the Wild (John Downer Productions, 2020) programında gösterildiği üzere, hedeflenen hayvan türüne tıpatıp benzeyen ve o türdeki hayvanlarla iletişim kurmasını sağlayabilecek hareketleri yapabilen robotlar da vardır. Örneğin, bir yavru ajan bebek goril, diğer gorillerle iletişim kurabilmek için elleriyle göğsüne vurabilme özelliğine sahiptir. Bu tarzdaki robotlar, Hanson Robotics'in geliştirdiği Sophie adlı humanoid robotun yarattığı kadar tedirginlik yaratmaz. Bu tedirginlik, insanlar ve robotları ayıran çizginin gün geçtikçe bulanıklaşmasından kaynaklanıyor olabilir. Diğer bir yandan, yapay zekânın da gelişiyor olması başka bir endişe kaynağıdır. Stanley Kubrick' in 2001: Uzay Yolu Macerası (1968) ve Čapek' in R.U.R yapımı, yapay zekânın insan ırkının sonunu getirecek olan kıyamet olabileceği üzerinde durur.

$\mathrm{Bu}$ endişe, Detroit: Become Human'da irkçllığa varan bir ayrımcılık ile betimlenmiştir. Bu ayrımcilığın en rahatsız edici örneklerinden biri, androidlerin otobüsün arkasında, insanlardan ayrılmış ve koltuksuz bir bölmede ayakta seyahat etmeleri ile gösterilir. Betimlenen bu ayrımcılığın rahatsız edici yanı, video oyunda gösterilen bu ayrımcılığın gerçek hayattakileri andırmasıdır. Oyunun hikâyesindeki androidleri ayrıştırabilmek ve sonradan dışlayabilmek adına, ilk bakışta anlaşılabilen ve androidlerin yüzlerinin sağ tarafında yer alan yuvarlak ışık, toplumdaki herkese kimin android olduğu bilgisini verir. Oyuncu, Markus adındaki android karakterlerden bir tanesini kontrol ederek yolda yürürken, androidlerin işlerini ellerinden aldığını iddia eden bir grup protestocu Markus'un yolunu keser. Aynı sokakta yer alan başka biri, androidlerin Detroit'in çöküşünü getireceğine dair vaaz verir. Bu iki tepki de sadece insanların androidlere olan tutumunu değil, teknolojiye karşı olan genel duruşlarını da gösterir. Geleceğin belirsizliği bazılarında heyecan uyandırırken, diğerinde ise özden uzaklaşma ve dolayısıyla hayatın sonuna yaklaşma anlamına gelir. Bu bağlamda, transhümanizm toplumun hatırı sayılır bir bölümü için belirsizliğin habercisi olarak algılanabilir.

Androidlere karşı yapılan haksızlıkların başka bir örneği, oyuncu Kara adlı androidi kontrol ederken görülebilir. Kara'nın hizmetçi olarak çalıştığı evdeki küçük bir kız olan Alice, babası tarafından fiziksel şiddet görür. Bu şiddeti görmesi üzerine Kara, babayı etkisiz bırakmak için hiç zaman kaybetmez. Kızı alıp evden kaçarak, gece kalabilecekleri bir yer aramaya başlarlar. Gece kalınacak yer bulma görevi oyuncuya verilir. Oyuncu, geceyi terkedilmiş bir araçta ya da yıkık bir binada geçirmeyi tercih edebilir. Oyuncu aynı zamanda android karakteri insan kılığına sokup, geceyi sadece insanlar için olan bir otelde geçirmeyi deneyebilir. Oyuncunun yaptı̆̆ı her seçimden sonra, Alice, oyuncunun yaptığı seçimler hakkında kendi fikirlerini dile getirir. $\mathrm{Bu}$ yorumlar genel doğru/yanlış algısı üzerinedir. Örneğin, eğer oyuncu, karakteri insan kılığına sokabilmek adına bir kıyafet yıkama servisinden kıyafet çalarsa, küçük kız karakter, çalmanın ne kadar yanlış olduğundan bahseder. Diğer bir taraftan, oyuncunun tercihine bağlı olarak, Alice adlı karakter bir dükkândan para çalması için android karakter tarafından ikna edilebilir. Oyuncuya sunulan tercihlerdeki ahlaki özgürlük son derece geniştir. Bu da kişinin kendi tecrübesini şekillendirmesi açısından önemlidir.

Oyunda aynı zamanda Alice'ın Kara'ya karşı tutumundaki değişiklikleri gösteren görsel ve işitsel bildirimler bulunur. Ancak bu bildirimler, Brown ve Krzywinska'nın (2015: 200) Orcs Must Die adlı oyunda eleştirdiklerinden farklıdır. Orcs Must Die'daki görsel bildirimler oyuncunun karşısına çıkan engelleri aşması için bir araç olarak kullanılırken, Detroit: Become Human'da yer alan görsel bildirimler, oyuncu ve oyunun yapay zekâsı arasında olan ilişkideki değişimlerin bildirisidir. $\mathrm{Bu}$, insanların video oyunlar hakkındaki tutumu için önemli bir detaydır. Brown ve 
Krzywinska (2015: 197) tarafından verilen Crisis (Crytek, 2007), Halo: Combat Evolved (Bungie, 2001), ve Destiny (Bungie, 2014) gibi örneklerde, oyunlar sadece yapay zekâyı savaşta yok etmeye odaklanmışken, Detroit: Become Human gibi örnekler, video oyunların sadece yok etmek, üstünlük sağlamak ya da gerçekleştirilmesi zor fantezileri yaşamak için sağlanmış sanal ortamlardan çok daha fazlası olduğunu gösterir.

Detroit: Become Human'ın her bölümünde oyuncuya bir görev verilir ve kontrol edilen karakter ancak bu görevin uygun gördüğü alan içinde yönlendirilebilir. Oyun yapımcıları bu sanal sınırları daha sinematik ve göreve dayalı bir tecrübe sunabilmek için yaparlar. Ancak bu sınırların görsel tasarımı bile kendince semboliktir. Bu sınırlar saydam duvarlar şeklindedir ve üzerlerinde o anda aktif olan görevle ilgili ayrıntılar gösterir. Bu tip kısıtlamalar, androidlerin toplum içinde rahatça gezemeyeceklerini ve sadece işlevlerinin sınırları doğrultusunda var olabileceklerini simgeler.

Diğer bir yandan, oyuncunun dilediği gibi gezebileceği ve dünyayı keşfedebilecekleri oyunlar da vardir. Legend of Zelda: Breath of the Wild (Nintendo, 2017), Journey (Thatgamecompany, 2012), The Last Guardian (SIE Japan Studio, 2016), Ico (SIE Japan Studio, 2001), Shadow of The Collossus (SIE Japan Studio, 2005), Dark Souls (From Software, 2009) ve Bloodborne (From Software, 2015) gibi oyunlar, oyuncunun görevinin ne olduğuyla ilgili çok az bilgi verir. Bu tarzdaki oyunların daha çok keşif ve çevresel hikâye anlatımıyla ilgilidir. Hikâyeyi keşfetmenin yolu oyuncunun çevreyi incelemesinden geçer.

Oyuncunun kontrol ettiği üç android karakterden sonuncusunun adı Conner'dır: Cyberlife adlı şirketin polis güçleriyle çalışması için geliştirilen bir dedektiftir. Cyberlife, Detroit: Become Human evrenindeki androidleri üreten ve bakımını sağlayan şirketin adıdır. Yeni modellerden biri olan Conner, transhümanist fanteziyi ve hayal gücünü sembolize eden sıra dışı özelliklerle donanmıştır. Tüm androidler, tıpkı kan gibi işleyen mavi bir sıvı ile çalışır. Conner, bu mavi kanın kime ait olduğunu, diline sürterek anlayabilir. Dahası, cisimleri fiziksel olarak inceleyerek, hammadde, üretim geçmişleri ve kullanım şekilleri gibi bilgilere erişebilir. Conner'ın sahip olduğu bütün bu analitik yetenekler insanlar tarafından da yapılabilir. Ancak bu tür analitik süreçlerin tamamlaması insanlar için çok daha uzun zaman alır. Ancak Conner bu sonuçlara birkaç saniyede ulaşabilir. Gerçek hayattaki insanların becerilerinin ve bunların Conner'da bulunan geliştirilmiş halleri arasındaki bağlantı, transhümanist bakış açısının yansımasıdır. Oyunun geliştirilme sürecinde, gelecekteki teknolojilerin nasıl olabileceğini tahmin etmede, çoktan var olan teknolojilerin hızlandırılmış halini odak noktası olarak alınmıştır. Bu yüzden, video oyunlardaki yaratıcı ve sanatsal özgürlük geleceğin teknolojisini hayal etmeyi de içerir.

Conner'ın sahip olduğu daha ilginç olan özelliklerden biri, kendi benliğini yeni bir androide aktarabilmesidir. Oyuncunun yaptığı kararlardan ötürü Conner ölse bile, karakter, yaşamış olduğu tecrübeleri ve benliğini yeni bir Conner modeline transfer etmiş bir şekilde, sanki asıl ölümü hiç gerçekleşmemiş gibi, sonraki bölümlerde hikâyeye geri döner. Bu sadece insanların ölüm üzerinde hâkimiyet kurma arzularına bir örnek olmakla kalmaz. Bu aynı zamanda androidlerin, ölümsüzlük gibi, insanların ulaşamadığı bir şeyi başardıklarının örneğidir.

Eğer oyun Playstation platformunda oynanırsa, oyuncu her bölüm için yaptıkları seçimlerin, diğer oyuncular tarafından tercih edilme oranlarını yüzdelik olarak görebilir. Bu oranlar arkadaş listesi ve evrensel istatistikler olarak ikiye ayrilır. Bu oranlar, video oyunları ve oyun konsollarının sağlamış oldukları sunucu altyapısı ve çevrimiçi özellikler sayesinde sürekli güncellenir. Böylelikle, oyuncular sadece kendi hikâyelerini oluşturmakla kalmaz, ayrıca seçimlerinin genele vurulduğunda nerede durduğunu da görebilirler. Video oyunların sağladığı bu gibi veriler, sosyolojik çalışmalar için de değerli bir kaynak olabilir. İnsanların ahlaki 
tercihlerini sorgulamak üzerine yapılacak olan sosyolojik bir çalışma, hikâye içinde seçim yapmayı gerektiren oyunları bireylere oynatarak yürütülebilir.

\section{NIER: AUTOMATA ve DISTOPIK TEKNOLOJI}

NieR: Automata'da (Platinum Games, 2017) oyuncunun kontrol ettiği karakterin adı 2B'dir. İsimden de anlaşılabileceği gibi, 2B bir androidtir. Kelimenin İngilizce telaffuzu olan "to be" Türkçede 'var olmak' anlamına gelir. İsmin telaffuzu karaktere sade bir androidden daha fazlasını katar; var olma arzusu. 2B karakteri, posthümanizm konusuna uyar çünkü insanların artık var olmadığı bir dünyada insana benzerken, insanüstü becerilere sahiptir. NieR: Automata, robotların gitgide insan hayatının bir parçası olmaya başladığı bir dünyada insan olmanın kaçınılmaz sorunsalının ne demek olduğunu inceleyen felsefi bir yaklaşım benimser. Oyundaki robotlar, ölümden korkma ve hayatta kalma içgüdüsü gibi insansı duygular gösterirler. Bunun sebebi, oyunda geçen robotların insanları taklit etmeye programlanmış olmalarıdır. Ölümün eşiğinde, insanlar hayatta kalmak için yalvarmıştır ve robotlar bu davranışları taklit etmeyi öğrenmiştir. Oyuncu düşman robotları yok etmeye çalışırken, bu robotlar hayatları için yalvarır, kaçmaya çalışır ve organik hisleri olmamasına rağmen acı içinde kıvranırlar. Özellikle bu oyun mekaniği insanların kalplerindeki yok olma korkusuna dikkat çeker. İnsanlık teknolojinin getirdiği konforla her geçen gün daha da rahatlarken, muhtaç hale gelecekleri günden korkarlar. Postmodernizmde görüldüğü gibi, toplum işlevini yitirmeye başladığında, insanlar genellikle sebebini bulmaya ve hasar, tamir edebilecek hale gelmeden düzeltmeye çalışırlar. Getirdiği konfor ve gelişimin yanında, teknolojinin topluma olan uyum sürecinde en önemli konulardan biri, teknolojinin var olan insan hayatı ve eğilimleri ile nasıl ilişki kurduğudur. NieR: Automata' daki hikâyenin odaklandığı noktalardan biri, robotların doğuşu ve gelişmesiyle daha belirginleşen toplumsal kontrolün muhtemel kaybının oluşturdu endişe ve korkudur.

Nier: Automata'nın hikâyesi klasik stildeki giriş, gelişme ve sonuç olarak anlatılmaz. Video oyunlar için bile sıra dışı sayılabilecek bir hikâye anlatım şekli vardır. Oyunun toplamda yirmi altı sonu vardır. Bu sonlardan beşi yapımcıların asıl son olarak hazırladıklarındandır. Hikâye, 2B adlı karakterin tanrıyı bulup, onu öldürüp öldüremeyeceğini sorgulamasıyla başlar. İnsanların soyunun tükendiği bir dünyada, androidler varlıklarının amacını sorgular. Arayışları üzerine, çeşitli ahlak kodları benimseyen klanlar ortaya çıkar. Bunların içinde, nesillerin devam etmesi için çalışıp küçükleri kollayan, insan dünyasında var olan din toplulukları gibi topluluklar kuran ve hayata hedonist bir biçimde bakan farklı gruplar vardır. Bu robotlar oyuncu tarafindan kontrol edilen androidin saldırısına uğradıklarında, bazıları geri saldırmaz. Bazı robotlar, önceden gözlemledikleri insanları taklit edip, savaştan kaçmaya çalışıp, acı çektiklerini söylerler. Tıpkı Android'ler Elektrikli Koyun Düşler mi? (Dick, 1968) ve Bladerunner (Scott, 1982) yapımlarda işlenilen robotların insanlarmışcasına acı çekebilme ve yaşamak mücadelesi verme temaları gibi, Detroit: Become Human ve NieR: Automata gibi video oyunlarda da benzer temalar işlenmiştir. Detroit: Become Human'daki Conner karakterine benzer bir şekilde, NieR: Automata'daki androidler, benliklerini yeni androidlere transfer edebilirler. Bu benlik aktarma Richard Morgan'ın Değiştirilmiş Karbon (2018) kitabında da işlenmiştir. Benzer konular çeşitli hikâye anlatım stilleriyle işlenmiştir. Bu bağlamda video oyunların birçok temayı işlemiş olması, sanat endüstrideki varlıklarını güçlendirir. Yapım kaliteleri arttıkça, video oyunlar gittikçe dikkat çeker. Diğer bir yandan, Değiştirilmiş Karbon bir Netflix serisi haline de getirilmiştir. Bu yüzden hikâyeler birçok değişik formatta tekrar betimlenebilir. Kitap olarak popülerlik kazanmış bir yapımın filminin ve oyununun çıkması artık sıkça rastlanılan bir olaydır. Bu bağlamda, video oyunların yine finansal kazanım kaygısıyla başarılı olan hikâyeleri, oyun mekanikleri kurmak için bir temel olarak kullandığı akla gelebilir. Serinin popülerliğinden faydalanmak için, diğer 
sanat türlerinde olduğu gibi mutlaka video oyun sektörü de yapımlar piyasaya sürmüştür. Ancak bu yapımların varlı̆̆ı, video oyunların bütünü için bir damga oluşturmamalıdır. Popüler kitap serilerinin filmleri de vardır ve kitaptan uyarlanan filmlerin varlığı, film endüstrisinin tamamını eleştirmek için bir sebep olarak kullanılmaz. Aynı durum, video oyunlar için de geçerlidir. Belli başlı yapımlara odaklanarak bütün video oyunlar için çıkarımda bulunmak mümkün değildir.

Mümkün olsaydı bile, video oyunları bu bağlamda değersiz kılmak yine zayıf bir eleştiri olurdu. Video oyun olarak piyasaya çlkan ve sonrasında kitaba ve/veya filme dönüşen birçok yapım vardır. Assassin's Creed markası video oyun olarak başlayıp, interaktif müze uygulamalarına kadar birçok değişik dalda eseri kemerinde tutan bir fikir mülküdür. Bunun yanında Dedektif Pikachu (Letterman, 2019), Kirpi Sonic (Fowler, 2020) ve Tomb Raider (Uthaug, 2018) gibi ünlü oyun karakterlerinin film adaptasyonları, sanatsal stiller arasındaki adaptasyonların tek taraflı olmadığının göstergesidir.

Androidlerin benliklerini aktarmaları virüslerden etkilenmelerine sebep olabilir. $\mathrm{Bu}$ da teknolojinin negatif bir yönünün göstergesidir. NieR: Automata'nın hikâyesini bitirince, oyuncu aynı hikâyeyi başka bir karakterin bakış açısından tekrar oynayıp, ilk oynanışta gösterilmemiş olan ayrıntıları öğrenebilir. Oyuncu aynı oyunu birkaç kez bitirerek, farklı sonlara ulaşabilir. Oyunun beşinci ve hikâyenin bütününe göre sonuncu bitişe ulaşılınca, oyuncudan, oyundaki ilerlemesini kaydetmesi için bir mini oyun oynaması istenir. Bu mini oyunda, oyuncudan ekranda çıkan yapımcıların isimlerini yok etmesi istenir. Ancak bu mini oyunun tek bir oyuncunun tamamlaması mümkün değildir. Eğer oyuncu bu imkânsız meydan okumadan çekilmeyi seçerse, oyun onlara pes edip etmediklerini sorarak hayatın anlamını sorgular. Oyuncu, bu olasılıksızlığa rağmen devam etmeyi seçerse, oyun tarafından ödüllendirilir. Oyunun sunduğu yardım, bu mini oyunu geçmek için diğer oyunculardan yardım alabilme iznidir. Ancak oyuncunun bu yardımı alabilmesi için, saatlerce uğraşarak oyunda ilerleyip oluşturdukları kayıt dosyalarını feda etmeleri gerekir. Yani asıl sona ulaşmak bir nevi her şeyi kaybetmek demektir. Oyuncunun bütün ilerlemesi silinir ve sonradan aynı kayıt dosyası üzerinden devam edemez. Gerçek sonu görmenin bu ağır bedeli, gerçek hayattaki ölüm gibidir. Böylesine geleneklere uymayan bir hikâye anlatış biçimi benimseyerek, NieR: Automata hayatın döngüsüne dikkat çeker ve imkânsız gibi görünen durumların üstesinden gelebilmek için cesaretin ve fedakârlığın önemini vurgular. İnsanlar olmadan yaşayan androidlerin ve robotların olmadığı bir dünyayı keşfederken, oyun taze bir hikâye anlatım biçimiyle oyunculara gerçek kayıp yaşama hissini ve başkalarına yardım edebilme onurunu tattırır.

\section{DEUS EX: MANKIND DIVIDED ve SİBERNETIKK GELISSTIIRMELER}

İnsan hayatının teknolojiyle buluştuğu diğer bir alansa sibernetik geliştirmelerdir. Deus Ex (Eidos -Montréal, 2016) dünyasında, insan vücudu ve teknolojinin birleşimi, talihsiz bir kazanın sonrasında iyileşmek için kendi üzerinde deneyler yapan bir bilim adamıyla başlamıştır. Ancak insan vücudu, sibernetik geliştirmeleri büyük ölçüde reddeder ve denenmesi hususunda sağlık problemlerine yol açar. Sağlık konusundaki endişelere rağmen, sibernetik geliştirmeler yaygınlaşır. Geliştirmelerin yol açtığı sağlık problemlerini çözmek adına piyasaya pahalı bir ilaç sürülür. Ancak bu ilaç geliştirmelerin yol açtığı problemleri etkisiz kılarken, zamanla bağımlılığa sebebiyet verir. Deus Ex oyunlarında betimlenen evren teknolojinin distopik betimlenişini benimser. Oyunun mekanikleri teknolojinin üzerine kurulmuş olsa da oyun teknolojinin muhtemel tehlikelerinin altını çizmekten geri kalmaz. Video oyunlar transhümanizmi sadece üzerine hikâye inşa edebilecekleri bir temel olarak görmezler. Konuya yaklaşımları eleştirel olup, teknolojinin getirebileceği potansiyel tehlikeleri gösterebilirler. Bu eleştirel yaklaşım, video 
oyunların teknolojiye dair her zaman pozitif fikirleri olmadığını ve insanlığın gelecekte karşılaşabilecekleri problemleri görmezden gelmediklerini gösterir.

\section{SONUÇ}

Video oyunlar, transhümanizm ve posthümanizm gibi teknolojik öğelerin sıkça görüldüğü akımların işlenmesi için muhteşem dallardır. Sunduğu birçok yenilikle, posthümanizmi sadece konu olarak işlemekle kalmaz, oyuncuların bu kavramlarla aktif bir şekilde yoğrulmasını sağlar. Transhümanist karakterlerin ve temaların sıkça görüldügü video oyunlar, bir sanat dalı olarak, içinde teknolojiyi çokça barındırdığından, transhümanizmin başlıca yuvasıdır. Teknolojinin ilerlemesiyle, tıpkı insanların yaşayış biçimleri gibi hikâye anlatış biçimleri de gelişir. Teknoloji çağının sanatçıları olan oyun geliştiricileri, geleceğin nasıl şekilleneceğine dair fikirlerini, sürükleyici hikâyeler aracılığıyla aktarırlar. Video oyun sektörünün gelişimi, var olan sanat türleri için bir tehdit oluşturmaz. Bütün sanat dalları uyum içinde bir arada var olabilirler. Belirli bir sanat dalının popülerliği, diğer sanat dallarının geçerliliğini ya da sanatsal değerini azaltmaz. Sanat türlerindeki çeşitlilik bir zenginliktir. Video oyunlar eleştirildiğinde, birkaç video oyunu temel alarak genele vurgulanan eleştirilerden kaçınılmalıdır. Eleştiride, video oyunun kendisine odaklanılmalı, yapılan eleştiriler bütün bir türü ya da yöntemi kapsamamalıdır. Bu çalışma sadece transhümanist karakterlerin işlenişine odaklanmamış, aynı zamanda video oyunların sahip olduğu potansiyelin de üzerinde sıkça durmuştur.

\section{KAYNAKÇA}

Blizzard Entertainment. (2015). Overwatch. Irvine, Kaliforniya, Amerika Birleşik Devletleri.

Bungie. (2014). Destiny. Bellevue, Washington, Amerika Birleşik Devletleri.

Bungie. (2001). Halo: Combat Evolved. Bellevue, Washington, Amerika Birleşik Devleteri.

Capcom. (2005) Resident Evil 4. Osaka, Japonya.

CD Projekt RED. (2020). Cyberpunk 2077. Varşova, Polonya.

Crytek. (2007). Crysis. Frankfurt, Almanya.

Čapek, K. (1920). R.U.R (trans. Caludia Novach-Jones). Çek Cumhuriyeti.

Dick. P. K. (1982). Blade Runner (Directed by Ridley Scott). Kanada.

Dick. P. K. (2010). Do Androids Dream of Electric Sheep?. Doubleday. 1968, Kanada.

Eidos- Montréal. (2016). Deus Ex: Mankind Divided. Montreal, Kanada.

Epic Games. (2017). Fortnite. Cary, Kuzey Carolina, Amerika Birleşik Devletleri.

Fowler, J. (2020). Sonic the Hedgehog. Amerika Birleşik Devletleri.

Fox Business. (2019). 'Assassin's Creed: Unity' could help with Notre Dame Restoration [video dosyası]. https://www.youtube.com/watch?v=vf4z7GkmlhY adresinden alınmıştır. (Erişim Tarihi: 22 Temmuz 2020).

From Software. (2015). Bloodborne. Tokyo, Japonya

From Software. (2009). Darksouls. Tokyo, Japonya.

Glukhovsky, D. A. (2002). Metro 2033. Rusya. 
Kojima Productions. (2019). Death Stranding. Shinagawa Şehri, Tokyo, Japonya.

Kotaku. (2019). Keanu Reeves Reveals Cyberpunk 2077 Release Date at E3 2019 [video dosyası]. https://www.youtube.com/watch?v=59pvij73-N0 adresinden alınmıştır. (Erişim Tarihi: 22 Temmuz 2020).

Krzywinska T., and Brown D. (2015) Games, Gamers and Posthumanism. In: Hauskeller M., Philbeck T.D., Carbonell C.D. (eds) The Palgrave Handbook of Posthumanism in Film and Television. Palgrave Macmillan, Londra

Kubrick, S. (1968). 2001: A Space Odyssey. Birleşik Krallık, Amerika Birleşik Devletleri.

Letterman, R. (2019). Detective Pikachu. Amerika Birleşik Devletleri, Japonya.

Moffit, M. [AsapSCIENCE]. (2014). Can Video Games Make You Smarter? [video dosyası]. https://www.youtube.com/watch?v=OOsqkQytHOs adresinden alınmıştır. (Erişim Tarihi: 22 Temmuz 2020).

Morgan, R. (2018). Altered Carbon. Gollanex, Büyük Britanya.

Nintendo. (2014). Legend of Zelda: Breath of the Wild. Kyoto, Japonya.

Oxford Learner's Dictionary. (2020) Consumer. Oxford sözlügünden alınmıştır: https://www.oxfordlearnersdictionaries.com/definition/english/consumer (Erişim Tarihi: 23 Temmuz 2020).

PlatinumGames. (2017). NieR: Automata. Osaka, Japonya.

Quantic Dream. (2018). Detroit: Become Human. Paris, Fransa.

Quantic Dream. (2013). Beyond Two Souls. Paris, Fransa.

Remedy Entertainment. (2016). Quantum Break. Espoo, Finlandiya.

Riot Games. (2009). League of Legends. West Los Angeles, Kaliforniya, Amerika Birleşik Devletleri. Robot Entertainment. (2011). Orcs Must Die. Plano, Teksas, Amerika Birleşik Devletleri.

Rockstar Games. (2013). Grand Theft Auto V. Edinburgh, İskoçya.

Sapkowski, A. (1993) The Last Wish: Witcher. Polonya.

SIE Japan Studio. (2001). Ico. Tokyo, Japonya.

SIE Japan Studio. (2015). Shadow of the Colossus. Tokyo, Japonya.

SIE Japan Studio. (2016). The Last Guardian. Tokyo, Japonya.

SIE Santa Monica Studio. (2010). God of War 3. Santa Monika, Kaliforniya, Amerika Birleşik Devletleri.

Spy in the Wild. (2020). Robot spy gorilla infiltrates a wild gorilla troop I Spy in The Wild - BBC [video dosyası]. https://www.youtube.com/watch?v=rh9PwFvMS0I adresinden alındı. (Erişim Tarihi: 23 Ocak 2020).

Studio MDHR. (2017). Cuphead. Oakville, Kanada.

Tech Insider. (2018, March 29). Robotic Fish Could Revolutionize How We Study the Ocean [video dosyası]. https://www.youtube.com/watch?v=PM-gW7xtZgY adresinden alındı. (Erişim Tarihi: 22 Temmuz 2020).

Telltale Games. (2009). Sam \& Max. San Rafael, Kaliforniya, Amerika Birleşik Devletleri. 
Telltale Games. (2009) Wallace \& Gromit. San Rafael, Kaliforniya, Amerika Birleşik Devletleri.

Telltale Games. (2010). Back to the Future. San Rafael, Kaliforniya, Amerika Birleşik Devletleri.

Telltale Games. (2011). Jurassic Park: The Game. San Rafael, Kaliforniya, Amerika Birleşik Devletleri.

Telltale Games. (2012). The Walking Dead. San Rafael, Kaliforniya, Amerika Birleşik Devletleri.

Telltale Games. (2013). The Wolf Among Us. San Rafael, Kaliforniya, Amerika Birleşik Devletleri.

Telltale Games. (2015). Minecraft: Story Mode. San Rafael, Kaliforniya, Amerika Birleşik Devletleri.

Telltale Games. (2016). Batman: The Telltale Series. San Rafael, Kaliforniya, Amerika Birleşik Devletleri.

Telltale Games. (2017). Guardians of the Galaxy. San Rafael, Kaliforniya, Amerika Birleşik Devletleri.

Thatgamecompany. (2012). Journey. Los Angeles, Kaliforniya, Amerika Birleşik Devletleri.

TV Tropes. (6, Şubat, 2020) Easy-Mode Mockery Action Games. Retrieved from TV Tropes: https://tvtropes.org/pmwiki/pmwiki.php/Main/EasyModeMockery (Erişim Tarihi: 22 Temmuz 2020).

Ubisoft Entertainment. (2014). Assassin's Creed Unity. Montreal, Quebec, Kanada.

Uthaug, R. (2018). Tomb Raider. Kamboçya.

Valve Corporation. (2012). Counter Strike Global Offense. Bellevue, Washington, Amerika Birleşik Devletleri.

Valve Corporation. (2013). Dota 2. Bellevue, Washington, Amerika Birleşik Devletleri.

Vikipedi. (2020) Grand Theft Auto V. Vikipedi'den alındı: https://en.wikipedia.org/wiki/Grand_Theft_Auto_V (Erişim Tarihi: 27 Şubat 2020).

Wolf, Mark J. P. and Perron, Bernbard. (2003). The Video Game Theory Reader. New York. Routledge. 2003 